\title{
Pyrogenicity of hyaluronic acid hydrogel cross-linked by divinyl sulfone for soft tissue augmentation
}

\author{
Jin-Tae Kim ${ }^{1}$, Jae-Ha Choi ${ }^{1}$, Deuk-Yong Lee ${ }^{2 *}$ \\ ${ }^{1}$ Department of Advanced Materials Engineering, Chungbuk National University, Cheongju, Korea \\ ${ }^{2}$ Department of Materials Engineering, Daelim University College, Anyang, Korea; *Corresponding Author: dylee@daelim.ac.kr
}

Received 3 March 2010; revised 23 April 2010; accepted 29 April 2010.

\begin{abstract}
Hyaluronic acid hydrogels (HAHs) were synthesized by immersing the micro-beads in phosphate buffered saline solution to assess shortterm biocompatibility of the gels by means of the rabbit pyrogen test and the bacterial endotoxin test. The rise in body temperature of 3 male New Zealand white rabbits weighing about 2 3 kg (12 16 weeks old) following intravenous injection of the test article $(10 \mathrm{~mL} / \mathrm{kg})$ was monitored at $\mathbf{3 0} \mathrm{min}$ intervals in $\mathbf{3} \mathrm{h}$ to examine the pyrogenicity. No rabbits showed an individual rise in temperature of $0.5^{\circ} \mathrm{C}$ or more above its respective control temperature. The temperature rises of the rabbits after injection were $0.12^{\circ} \mathrm{C}, 0.13^{\circ} \mathrm{C}$, and $0.18^{\circ} \mathrm{C}$, respectively, suggesting that $\mathrm{HAH}$ meets the requirements for the absence of pyrogens. The bacterial endotoxin test revealed that the concentration of endotoxins required to cause the lysate to clot under standard conditions was $<0.125 \mathrm{EU} / \mathrm{mL}$. Comparing the HAHs that was synthesized in this experiment to the ones approved by FDA, the amount of $<0.125 \mathrm{EU} / \mathrm{mL}$ endotoxins is relatively safe and effective. The test solution did not contain any interfering factors under the experimental conditions used. It is conceivable that the HAHs are likely to be suitable injectable dermal filler for facial soft tissue augmentation due to the absence of pyrogens.
\end{abstract}

Keywords: Hyaluronic Acid Hydrogel; Injectable Dermal Filler; Pryogenicity; Endotoxin; Interfering Factor; Soft Tissue Augmentation

\section{INTRODUCTION}

Hydrogels as injection augmentation of facial soft tissue have attracted immediate attention due to their regenera- tion properties of various tissues, mechanical properties, softness, oxygen permeability, similarities the body's own highly hydrated composition and excellent biocompatibilities [1-8]. They demonstrated their efficacy in correcting aesthetic defects such as congenital or hypovolumetries, nasolabial furrows, forehead, glabella wrinkles, cheekbone, chin hypovolumetry and lip augmentation. They are known to be highly swollen and insoluble networks that can be used to entrap cells. It is noted that higher equilibrium swelling promotes nutrient diffusion into the gel and cellular waste removal out of the gel, while the insolubility provides the structural integrity necessary for tissue growth $[1,2]$.

Among natural polymers, such as collagen, gelatin, fibrin, alginic acid, chitosan and hyaluronic acid (HA), crosslink-stabilized HA is highly acknowledged as a naturally derived injectable filler due to its longevity of correction, a reduced risk of immunogenicity and hypersensitivity, and its controllable mechanical and degradation properties [1,7]. HA is a linear polysaccharide formed from disaccharide units containing $N$-acetyl- $D$ glucosamine and glucuronic acid $[2,8]$. HA molecule is stabilized to produce cross-linked gel suitable for softtissue implantation, resulting in improving its resistance to enzymatic degradation within the dermis without compromising its biocompatibility.

HA hydrogels cross-linked by divinyl sulfone (HAHs) were prepared by immersing the micro-beads in phosphate buffered saline solution $\left(\mathrm{NaH}_{2} \mathrm{PO}_{4}\right)$ [9]. HAHs for soft tissue augmentation are reported to be biologically inert and non-allergic and do not require allergy testing before implantation. Prior to the evaluation of long-term toxicity (genotoxicity) and carcinogenicity after the injection because they have been used within the dermis for several months, it is necessary to examine adverse and allergic reactions of the $\mathrm{HAH}$, such as short-term pyrogenicity [5]. Although the rabbit pyrogen test has played a key role to control pyrogenicity of the drugs for long time, the test has limitations due to insufficient accuracy. The bacterial endotoxin test, which is based on 
highly sensitive clotting of Limulus Amoebocyte Lysate (LAL) by endotoxin, has been applied in place of the pyrogen test. However, the LAL test has also limitations in detection of such in vivo synergistic effect of endotoxin and the drugs [10]. The pyrogenicity of the HAH is investigated to assess the short-term biocompatibility by means of the rabbit pyrogen test and the LAL test (gel-clot method) $[10,11]$.

\section{METHODS}

\subsection{Materials}

HA solutions of $4.0 \mathrm{wt} \%$ concentration were prepared by dissolving a $3.2 \mathrm{~g}$ of sodium hyaluronate $\left(\mathrm{Mw}=1 \times 10^{6}\right.$ Da, Shiseido Co., Japan) in $8 \mathrm{~mL}$ of $0.05 \mathrm{~mol} / \mathrm{L} \mathrm{NaOH}$ at room temperature. $\mathrm{A} \mathrm{pH}$ in the range of 12 to 14 was achieved by adding $0.4 \mathrm{~mL}$ of $10 \mathrm{~mol} / \mathrm{L} \mathrm{NaOH}$ to the HA solution. Then, the HA solution was placed in a solution hopper attached to the Masterflex L/S tubing pump (Cole Parmer, USA) and fed into a syringe equipped with a 14-gage metal needle at a flow rate of $0.2 \mathrm{~mL} / \mathrm{min}$. Micro-beads with diameters of 0.2 to $0.3 \mathrm{~mm}$ were fabricated by supplying compressed air with a pressure of 34.475 Pa along the HA solution nozzle. The nozzle was enclosed by a delivery tube with a diameter of $6 \mathrm{~mm}$ [9]. Micro-beads were collected into a solution mixture of $0.4 \mathrm{~mL}$ of divinyl sulfone $(\geq 98 \%$, Sigma and Aldrich, Germany) and $40 \mathrm{~mL}$ of 2-methyl-1-propanol (99\%, Aldrich), followed by a stirring process (140 160 rpm) for $24 \mathrm{~h}$ at room temperature. Then, the cross-linked micro-beads were immersed in ethanol for $0.5 \mathrm{~h}$ to clean the beads by removing impurities such as divinyl sulfone and 2-methyl-1-propanol. After 3-time cleaning in ethanol, micro-beads were dried at $60^{\circ} \mathrm{C}$ in vacuum (20 torr). The as-dried micro-beads were immersed in $80 \mathrm{~mL}$ of phosphate buffered saline solution $\left(\mathrm{NaH}_{2} \mathrm{PO}_{4}\right)$ for $2 \mathrm{~h}$ to obtain HAHs, as shown in Figure 1. The HAHs were then provided in a $1 \mathrm{~mL}$ sterilized syringe with luer-lok type capped.

\subsection{Rabbit Pyrogen Test}

Male New Zealand white rabbits weighing about $2 \sim 3 \mathrm{~kg}$ (12 16 weeks old) were employed for pyrogenicity. The material extract was prepared in the static conditions in sterile physiological saline solution $(1 \mathrm{~g}$ in $50 \mathrm{~mL})$ for 72 $\mathrm{h}$ at $37^{\circ} \mathrm{C}$, followed by centrifuging for $10 \mathrm{~min}$ at 3000 rpm and filtering (Whatman, Grade 4, England). Not more than $30 \mathrm{~min}$ prior to the injection of the test dose, the control temperature of each rabbit was determined. The control temperature is the base for the determination of any temperature increase resulting from the injection of a test solution. Rabbits, whose control temperatures did vary by more than $1^{\circ} \mathrm{C}$ from each other, were ex-

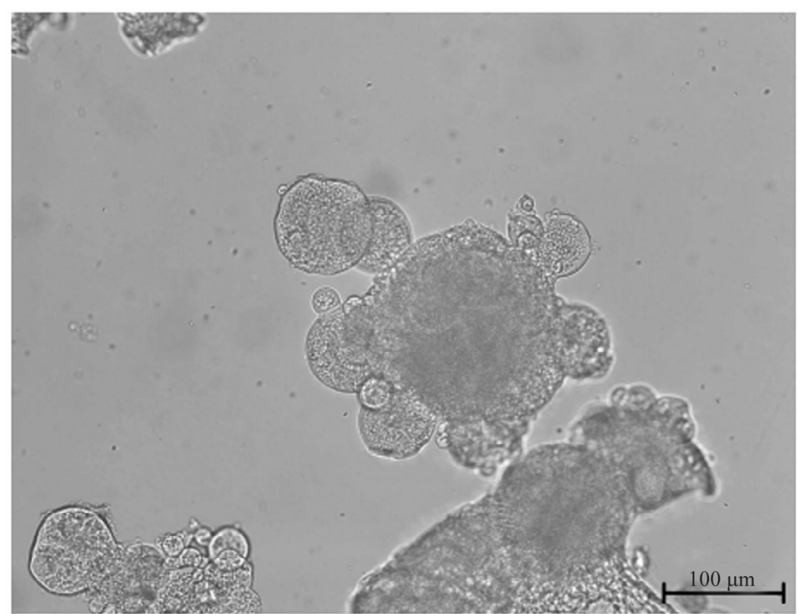

(a)

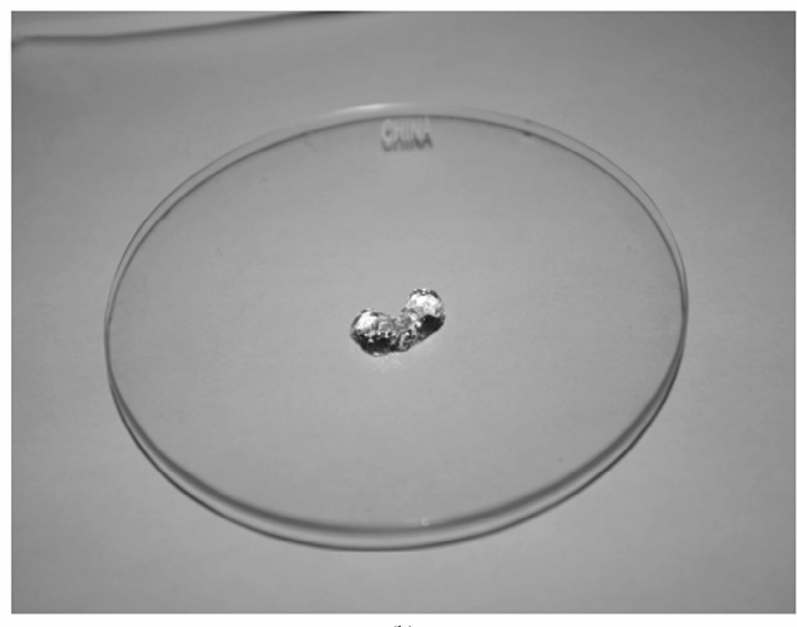

(b)

Figure 1. Photographs of (a) the micro-beads immersed in phosphate buffered saline solution and (b) hyaluronic acid hydrogels.

cluded. In addition, any rabbits having a temperature exceeding $39.8^{\circ} \mathrm{C}$ were also excluded. The test involved measuring the rise in body temperature of rabbits following intravenous injection of the test article and was designed for products that can be tolerated by the test rabbit in a dose not exceed $10 \mathrm{~mL} / \mathrm{kg}$ injected intravenously, within a period of not more than $10 \mathrm{~min}$. Injection was performed after warming the test solution to a temperature of $37 \pm 2{ }^{\circ} \mathrm{C}$.

After the injection, the body temperature is monitored at $30 \mathrm{~min}$ intervals in $3 \mathrm{~h}$. If no rabbit shows an individual rise in temperature of $0.5^{\circ} \mathrm{C}$ or more above its respective control temperature, the product meets the requirements for the absence of pyrogens. If any rabbit shows an individual temperature rise of $0.5^{\circ} \mathrm{C}$ or more, continue the test using 5 other rabbits. If not more than 3 of 8 rabbits show individual rises in temperature of $0.5^{\circ} \mathrm{C}$ or more and if the sum of 8 individual maximum 
temperature rises does not exceed $3.3^{\circ} \mathrm{C}$, the material under examination meets the requirements for the absence of pyrogens.

\subsection{In Vitro Endotoxin Test}

The pyrogens that almost invariably contaminate parenteral pharmaceuticals are bacterial endotoxins (lipopolysaccharides, LPS)-cell wall material from gram negative bacteria [10]. The LAL test detects only LPS, which caused extracellular coagulation of the blood of the horseshoe crab, Limulus polyphemus. The bacterial endotoxin test, which is based on highly sensitive clotting of LAL by endotoxin, has been applied in place of the pyrogen test for testing parenteral human drugs [10, 11]. The gel-clot testing was performed to detect bacterial endotoxin. The gel-clot method is based upon the reaction between bacterial endotoxin and a single test LAL (CAMBREX, Lot No. GL1403).

All glassware was depyrogenated for $4 \mathrm{~h}$ at $180^{\circ} \mathrm{C}$ and the test was carried out in clean-bench to avoid the endotoxin contamination. The material extract was prepared in the static conditions in LAL reagent water (BIO Whittaker, $1 \mathrm{~g}$ in $40 \mathrm{~mL}$ ) for $1 \mathrm{~h}$ at $37^{\circ} \mathrm{C}$. The concentration of endotoxins required to cause the lysate to clot under standard conditions is the labeled lysate sensitivity $(\lambda)$, expressed $\mathrm{IU} / \mathrm{mL}$. Endotoxin is expressed in International Unit (IU). One IU of endotoxin is equal to one Endotoxin Unit (EU). Standard solutions of at least four concentrations equivalent to $2 \lambda, 1 \lambda, 0.5 \lambda$, and $0.25 \lambda$ were prepared by diluting the standard endotoxin stock solution with LAL reagent water. A volume of the lysate solution was mixed with an equal volume of one of the standard solutions. The mixture was incubated for $60 \pm 2$ min at $37 \pm 1{ }^{\circ} \mathrm{C}$. Following $1 \mathrm{~h}$ of incubation at $37^{\circ} \mathrm{C}$, the test tube was examined by $180^{\circ}$ inversion for the presence of a stable solid clot. A clotted incubation mixture is considered to be a positive result. A result is negative if an intact gel is not formed. The test is not valid unless the lowest concentration of the standard solutions shows a negative result in all replicate tests. The end-point is the last positive result in the series of decreasing concentrations of endotoxin. The mean value of the logarithms of the end-point concentrations and then the antilogarithm of the mean value is calculated. The geometric mean end-point concentration is the measured sensitivity of the lysate solution. If this is not less than 0.5 and not more than 2 , the labeled sensitivity is confirmed and is used in the tests performed with this lysate. Solutions, as shown in Table 1 (A, B, C, and D), are prepared to confirm the labeled lysate sensitivity. The test is not valid unless both replicates of two positive control solutions $\mathrm{B}$ and $\mathrm{C}$ are positive and those of the negative control solution $\mathrm{D}$ are negative.

\section{RESULTS AND DISCUSSION}

The rise in body temperature of 3 Male New Zealand white rabbits following intravenous injection of the test article $(10 \mathrm{~mL} / \mathrm{kg})$ was monitored at $30 \mathrm{~min}$ intervals in $3 \mathrm{~h}$ to examine the pyrogenicity. It is found that the increase in body weight was normal, as summarized in Table 2. No mortality and abnormal clinical signs were detected. No rabbits showed an individual rise in temperature of $0.5^{\circ} \mathrm{C}$ or more above its respective control temperature, as shown in Figure 2. The temperature rises of the rabbits after injection were $0.12^{\circ} \mathrm{C}, 0.13^{\circ} \mathrm{C}$, and $0.18^{\circ} \mathrm{C}$, respectively, suggesting that the $\mathrm{HAH}$ meets the requirements for the absence of pyrogens.

The gel-clot technique allows detection or quantification of endotoxins and is based on clotting of the lysate in the presence of endotoxins [11]. The concentration of endotoxins required to cause the lysate to clot under standard conditions is the labeled lysate sensitivity. To ensure both the precision and validity of the test, the

Table 1. Solutions for the gel-clot test.

\begin{tabular}{ccc}
\hline solution & $\begin{array}{c}\text { endotoxin concentration/solution to } \\
\text { which endotoxin is added }\end{array}$ & replicates \\
\hline A & None/sample solution & 2 \\
\hline B & $2 \lambda /$ sample solution & 2 \\
\hline C & $2 \lambda /$ LAL reagent water & 2 \\
\hline D & none/ LAL reagent water & 2 \\
\hline
\end{tabular}

Table 2. Body weight changes.

\begin{tabular}{ccc}
\hline Rabbits & Receipt day $(\mathrm{g})$ & Injection day $(\mathrm{g})$ \\
\hline 1 & 2268.6 & 2377.8 \\
2 & 2161.6 & 2276.0 \\
3 & 1957.4 & 2091.1 \\
\hline Mean & 2129.2 & 2248.3 \\
SD & 158.1 & 145.3 \\
\hline
\end{tabular}

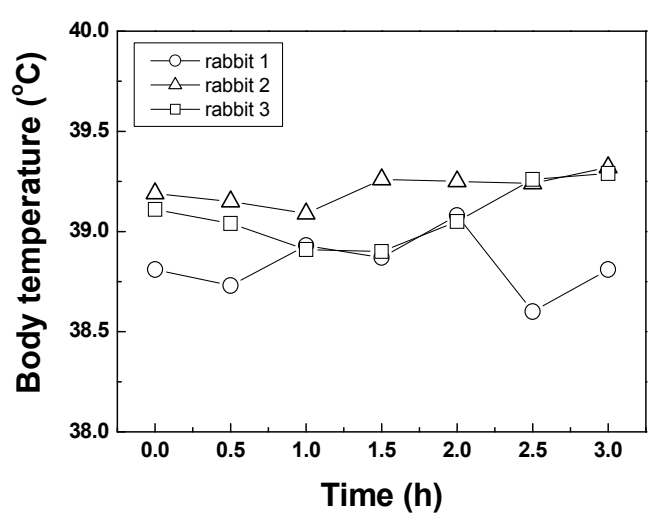

Figure 2. The variation in body temperature of 3 Male New Zealand white rabbits after intravenous injection of the test article. Note that the body temperature is monitored at $30 \mathrm{~min}$ intervals in $3 \mathrm{~h}$. 
labeled lysate sensitivity and the test for interfering factors were performed by using solutions for the gel-clot test as summarized in Table 1. The end-point is the last positive results in the series of decreasing concentrations of endotoxin. The geometric mean end-point concentration is the measured sensitivity of the lysate solution. The mean value of the logarithms of the end-point concentrations is equivalent to the antilogarithm of the mean value, $($ Antilog Mean $=0.12 \mathrm{EU} / \mathrm{mL})$. The antilogarithm of the mean value is calculated to be -0.921 . If the geometric mean end-point concentration of $0.12 \mathrm{EU} / \mathrm{mL}$ is not less than $0.5 \lambda(0.06)$ and not more than $2 \lambda(0.24)$, the labeled sensitivity is confirmed and is used in the tests performed with this lysate, as shown in Table 3 . For the lysate to clot under standard conditions, $<0.125$ $\mathrm{EU} / \mathrm{mL}$ was found to be the required concentration of endotoxins. The material extract was prepared in the static conditions in LAL reagent water for $1 \mathrm{~h}$ at $37^{\circ} \mathrm{C}$ [11]. After considering the dilution factor, the final concentration of endotoxin was determined to be $<0.005$ EU/mg. According to FDA's "Summary of Safety and Effectiveness Data," endotoxin concentrations are 0.5 $\mathrm{EU} / \mathrm{mL}, 20 \mathrm{EU} /$ syringe, $0.08 \mathrm{EU} / \mathrm{mL}$ for the three approved injectable dermal HAH fillers in market, respectively [12-14]. Comparing the HAHs that was synthesized in this experiment to the ones approved by FDA, the amount of $<0.125 \mathrm{EU} / \mathrm{mL}$ endotoxins is relatively safe and effective [12-14].

The test for interfering factors is repeated when any changes are made to the experimental conditions that are likely to influence the result of the test. The test is not valid unless all replicates of solutions $\mathrm{A}$ and $\mathrm{D}$ show no reaction and the result of solution $\mathrm{C}$ confirms the labeled lysate sensitivity. If the sensitivity of the lysate determined with solution B is not less than 0.5 and not greater than 2, the test solution does not contain interfering factors under the experimental conditions used. Otherwise, the solution interferes with the test. Test results, as listed in Table 4, implied free of interfering factors because solutions $\mathrm{A}$ and $\mathrm{D}$ showed reaction and the lysate sensitivity with solution $\mathrm{B}$ was within the experimental range (0.5 2) [11].

Table 3. Test for confirmation of the labeled lysate sensitivity.

\begin{tabular}{|c|c|c|c|c|c|}
\hline \multirow{2}{*}{$\begin{array}{l}\text { No. } \\
\text { of } \\
\text { time }\end{array}$} & \multicolumn{4}{|c|}{ Endotoxin dilution $(\mathrm{EU} / \mathrm{mL})$} & \multirow{2}{*}{$\begin{array}{l}\text { End- } \\
\text { point } \\
(\mathrm{EU} \\
/ \mathrm{mL})\end{array}$} \\
\hline & $\begin{array}{l}0.24 \\
(2 \lambda)\end{array}$ & $\begin{array}{l}0.12 \\
(1 \lambda)\end{array}$ & $\begin{array}{lc}0.06 & 0.03 \\
(0.5 \lambda) & (0.25 \lambda)\end{array}$ & LAL RW* & \\
\hline 1 & + & + & - & - & 0.12 \\
\hline 2 & + & + & - & - & 0.12 \\
\hline 3 & + & + & - & - & 0.12 \\
\hline 4 & + & + & - & - & 0.12 \\
\hline
\end{tabular}

+ : positive, -: negative, RW: reagent water.
Table 4. Test for interfering factors.

\begin{tabular}{clllllll}
\hline \multirow{3}{*}{ Solution } & \multirow{6}{*}{$\begin{array}{l}\text { No. } \\
\text { of }\end{array}$} & \multicolumn{5}{c}{$\begin{array}{c}\text { Endotoxin dilution } \\
(\mathrm{EU} / \mathrm{mL})\end{array}$} & $\begin{array}{c}\text { End-point } \\
\text { time }\end{array}$ \\
\cline { 3 - 6 } & & 0.24 & 0.12 & 0.06 & 0.03 & \\
& & $(2 \lambda)$ & $(1 \lambda)$ & $(0.5 \lambda)$ & $(0.25 \lambda)$ & \\
\hline \multirow{3}{*}{$\mathrm{B}$} & 1 & + & + & - & - & 0.12 \\
& 2 & + & + & - & - & 0.12 \\
& 3 & + & + & - & - & 0.12 \\
& 4 & + & + & - & - & 0.12 \\
\hline \multirow{2}{*}{$\mathrm{C}$} & 1 & + & + & - & - & 0.12 \\
& 2 & & + & + & - & - & 0.12 \\
\hline
\end{tabular}

*solution A: all positive, solution D: all negative.

\section{CONCLUSIONS}

Short-term biocompatibility of the HAHs prepared by immersing the micro-beads in phosphate buffered saline solution was evaluated by examining the rabbit pyrogen test and the bacterial endotoxin test. No rabbits showed an individual rise in temperature of $0.5^{\circ} \mathrm{C}$ or more above its respective control temperature after intravenous injection of the test article $(10 \mathrm{~mL} / \mathrm{kg})$ to 3 male New Zealand white rabbits. The temperature rises of the rabbits after injection were $0.12^{\circ} \mathrm{C}, 0.13^{\circ} \mathrm{C}$, and $0.18^{\circ} \mathrm{C}$, respectively, suggesting that the $\mathrm{HAH}$ meets the requirements for the absence of pyrogens. The concentration of endotoxins required to cause the lysate to clot under standard conditions was determined to be $<0.125 \mathrm{EU} / \mathrm{mL}$. Comparing the HAHs that was synthesized in this study to the injectable dermal fillers approved by FDA $(0.5$ $\mathrm{EU} / \mathrm{mL}$ ), the amount of $<0.125 \mathrm{EU} / \mathrm{mL}$ endotoxins is relatively safe and effective. The test solution was free of interfering factors under the experimental conditions used. It is suggested that the HAHs are likely to be suitable filler for facial soft tissue augmentation due to the absence of pyrogens.

\section{REFERENCES}

[1] Jeon, O., Song, S.J., Lee, K., Park, M.H., Lee, S., Hahn, S.K., Kim, S. and Kim, B. (2007) Mechanical properties and degradation behaviors of hyaluronic acid hydrogels cross-linked at various cross-linking densities. Carbohydrate Polymers, 70(3), 251-257.

[2] Monheit, G.D. and Coleman, K.M. (2006) Hyaluronic acid fillers. Dermatol Therapy, 19(3), 141-150.

[3] Kim, J.T. and Choi, J.H. (2009) Production and evaluation of hyaluronic acid gel for soft tissue augmentation. Biomaterials Research, 13(9), 105-108.

[4] Maas, C.S., Papel, I.D., Creene, D. and Stoker, D.A. (1997) Complications of injectable synthetic polymers in facial augmentation. Dermatologic Surgery, 23(10), 871-877.

[5] Hoffmann, C., Schuller-Petrovic, S., Soyer, H.P. and Kerl, H. (1999) Adverse reactions after cosmetic lip augmentation with permanent biologically inert implant materials. Journal of the American Academy of Dermatology, 40(1), 
100-102.

[6] Narins, R.S., Brandt, F., Leyden, J., Lorenc, Z.P., Rubin, M. and Smith, S. (2003) A randomized, double-blind, multicenter comparison of the efficacy and tolerability of restylane versus zyplast for the correction of nasolabial folds. Dermatologic Surgery, 29(6), 588-595.

[7] Ramires, P.A., Miccoli, M.A., Panzarini, E., Dini, L. and Protopapa, C. (2005) In Vitro and In Vivo biocompatibility evaluation of a polyalkylimide hydrogel for soft tissue augmentation. Journal of Biomedical Materials Research Part B: Applied Biomaterials, 72B(2), 230-238.

[8] Kogan, G., Soltes, L., Stern, R. and Gemeiner, P. (2007) Hyaluronic acid: A natural biopolymer with a broad range of biomedical and industrial applications. Biotechnology Letters, 29(1), 17-25.

[9] Kim, J.T., Kook, C.H. and Choi, J.H. (2009) Production equipment and method of polymer gel for bio-implanting.
Journal of Korean Society of Mechanical Technology, 11(2), 89-94.

[10] Ochiai, M., Yamamoto, A., Kataoka, M., Toyoizumi, H., Arakawa, Y. and Horiuchi, Y. (2007) A quantitative in vitro assay to detect biological activity of endotoxin using rabbit peripheral blood. Proceedings of the 6th World Congress on Alternative and Animal Use in the Life Science, 14(3), 641-645.

[11] (2002) European Pharmacopoeia, 4th Edition, Bacterial Endotoxins, 140-147.

[12] http://www.accessdata.fda.gov/cdrh_docs/pdf2/P020023b. $\mathrm{pdf}$

[13] http://www.accessdata.fda.gov/cdrh_docs/pdf5/P050033b. pdf

[14] http://www.accessdata.fda.gov/cdrh docs/pdf5/P050047b. pdf 